\title{
HOW SPINOPELVIC PARAMETERS ARE AFFECTED AFTER SURGICAL TREATMENT FOR SCHEUERMANN'S KYPHOSIS
}

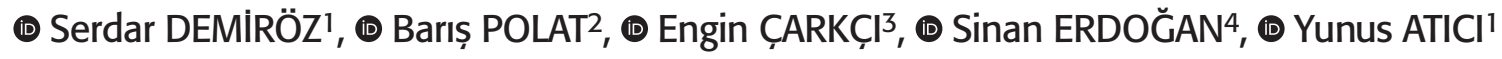 \\ ${ }^{1}$ Gebze Medicalpark Hospital, Clinic of Orthopedics and Traumatology, Kocaeli, Turkey \\ ${ }^{2}$ Kyrenia University Faculty of Medicine, Department of Orthopedics and Traumatology, Girne, Turkey \\ 3 Istanbul Training and Research Hospital, Clinic of Orthopedics and Traumatology, IIstanbul, Turkey \\ ${ }^{4}$ Istanbul Metin Sabancı Baltalimanı Bone Diseases Training and Research Hospital, Clinic of Orthopedics and Traumatology, İstanbul, Turkey
}

Objective: The relationship between the pelvis and spine is critical in global spinal alignment and sagittal imbalance and its associated compensatory mechanisms have been reported to correlate with negatively influenced quality of life. There are several studies evaluating the sagittal spinopelvic parameters (SSPs) in many areas of spinal disorders but studies evaluating the SSPs in Scheuermann's kyphosis (SK) are limited. To evaluate the effect of surgical treatment on SSPs in patients affected by SK.

Materials and Methods: The database of the institution was retrospectively reviewed to identify patients who underwent surgery for SK between the years of 2012 and 2015. Twenty-nine patients were included, and records of these patients were reviewed. Changes in pelvic incidence (PI), pelvic tilt (PT), sacral slope (SS), cervical lordosis (CL), thoracic kyphosis (TK), lumbar lordosis (LL), and the sagittal vertical axis (SVA) measurements were compared.

Results: There were no significant changes in PI, PT, SVA, and SS compared to preoperative values. There were decreases in TK and LL measurements, which were statistically significant.

Conclusion: Surgical treatment for SK seems to have little or no influence on changing SSPs.

Keywords: Kyphosis, pelvic tilt, pelvic incidence, sacral slope, sagittal vertical axis

\section{INTRODUCTION}

Scheuermann's kyphosis (SK) is a structural hyperkyphosis of the thoracic or thoracolumbar spine ${ }^{(21)}$. It is the most common cause of rigid hyperkyphosis and develops during adolescence with equal prevalence in both sexes and the incidence rate ranging from $0.4 \%$ to $8 \%(4,16)$. The diagnosis is based on the presence of thoracic kyphosis (TK) of $>40^{\circ}$ or thoracolumbar kyphosis of $>60^{\circ}$ and at least three consecutive vertebrae wedged at a minimum of $5^{\circ}$, as indicated on lateral spine imaging ${ }^{(23)}$. The etiology of the disease is unknown, but it is considered as multifactorial, with a strong genetic predisposition ${ }^{(15)}$. Although the first-line treatment of SK is usually conservative, surgical management is indicated in patients with progressive deformity exceeding $70^{\circ}$, progressive neurological deficit, severe back pain, or significant cosmetic deformity ${ }^{(16)}$. Although some authors have suggested the use of combined anterior and posterior approaches to maximize initial deformity correction, Ponte has reported that posterior fusion alone is sufficient to achieve satisfactory outcomes with lower complication rates than those of combined approaches ${ }^{(2.19)}$. The radiographic parameters include pelvic incidence (PI), pelvic tilt (PT), sacral slope (SS), cervical lordosis (CL), TK, lumbar lordosis (LL), and the sagittal vertical axis (SVA), collectively known as sagittal spinopelvic parameters (SSPs). The relationship between the pelvis and spine is critical in global spinal alignment and sagittal imbalance and its associated compensatory mechanisms have been reported to correlate with negatively influenced quality of life $^{(12,22)}$. There are several studies evaluating the SSPs in many

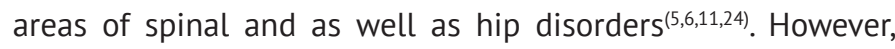
studies evaluating the SSPs in SK are limited. We tried to study the effect of surgical treatment on SSPs in patients affected by SK.

\section{MATERIALS AND METHODS}

The database of the institution was retrospectively reviewed to identify patients who underwent surgery for thoracic SK between the years of 2012 and 2015. The records of these patients were reviewed and the patients with postural kyphosis, congenital spine deformity, neuromuscular disease, associated 
spondylolisthesis or spondylolysis, the presence of scoliosis, patients who underwent previous spinal surgeries, and patients with lack of X-ray controls were excluded. Finally, 29 patients with SK were included in the study. The diagnosis of SK was based on the radiological criteria reported by Sorensen ${ }^{(23)}$. The indications for surgery were kyphosis with a curve greater than $70^{\circ}$, conservative treatment resistant back pain or an unacceptable cosmetic appearance. All the patients had normal neurological examination records. Following parameters evaluated on preoperative and postoperative radiographs are SVA, TK, LL, PI, SS, CL and PT (Figure 1). SVA is the horizontal distance from the posterosuperior corner of the sacrum to the C7 plumb line; TK is the Cobb angle between superior endplate of $\mathrm{T} 1$ vertebra and the inferior endplate of T12 vertebra; LL is the Cobb angle between the superior endplate of S1 vertebra and the superior endplate of L1 vertebra; PI is the angle between a line perpendicular to the upper sacral plate at its midpoint and the line connecting this midpoint to the middle axis of the femoral heads; SS is the angle between the sacral plate and the horizontal line; $\mathrm{CL}$ is the angle determined by measuring the angle between the straight lines that connect the posterior edges of the $\mathrm{C} 2$ and $\mathrm{C} 7$ vertebrae; PT is the angle between the vertical line and the line joining the middle of the sacral plate and the axis of the femoral heads ${ }^{(3,7,13,20)}$. Matchedpair analysis was used to compare radiological measurements before and after surgery. A $p$ value threshold of $<0.05$ was chosen to define statistical significance. Analysis of changes in postsurgical SSPs compared to preoperative values was performed, and encountered complications were described. The measured values were compared with those reported in literature.

\section{RESULTS}

Twenty-nine patients were included in the study, of which 25 were male and 4 were female. The mean age was $20.75 \pm 5.38$ years (range $=14-36$ years). There were 3 patients that had complications after surgical treatment: two proximal junctional kyphosis managed by revision surgery and one hemothorax that needed intervention by thoracic surgery. There were no significant changes in PI, PT, SVA, and SS compared to preoperative values $(p>0.05)$ (Table 1$)$. TK passed from an average $61.34 \pm 15.55$ preoperatively to an average $38.27 \pm 13.49$ $(p<0.05)$. LL passed from an average $66.37 \pm 11.22$ preoperatively to an average $50.93 \pm 15.66(p<0.05)$, and $S L$ passed from an average $24.32 \pm 19.87$ preoperatively to an average $25.75 \pm 15.74$ $(p>0.05)$.

\section{DISCUSSION}

The sagittal spinal alignment analysis has become popular and correlation between SSPs and various spinal and pelvic diseases has been searched in the last decades ${ }^{(14,18,19)}$. Afterward, SK is the most common cause of sagittal spinal deformity in adolescence, but unexpectedly very few studies evaluating the

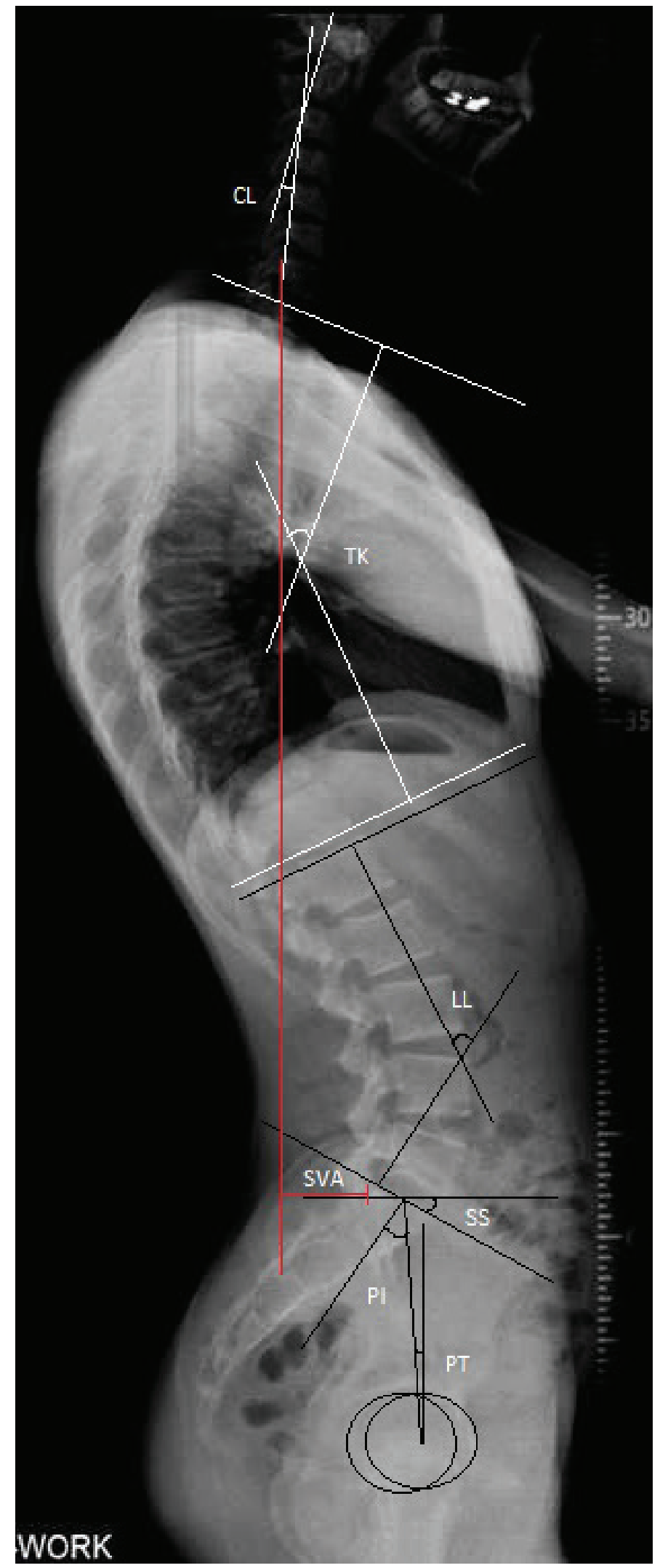

Figure 1. Measurement techniques for assessment of sagittal balance and spinopelvic parameters

CL: Cervical lordosis, TK: Thoracic kyphosis, LL: Lumbar lordosis, PI: Pelvic incidence, SS: Sacral slope, PT: Pelvic tilt, SVA: Sagittal vertical axis 
Table 1. Changes in spinopelvic parameters

\begin{tabular}{llll}
\hline & Preoperative & Postoperative & $p$ value \\
\hline CL & $24.32 \pm 19.87$ & $25.75 \pm 15.74$ & $>0.05$ \\
\hline TK & $61.34 \pm 15.55$ & $38.27 \pm 13.49$ & $<0.05$ \\
\hline LL & $66.37 \pm 11.22$ & $50.93 \pm 15.66$ & $<0.05$ \\
\hline PI & $41.93 \pm 13.18$ & $42.37 \pm 14.38$ & $>0.05$ \\
\hline SS & $33.10 \pm 10.57$ & $31.31 \pm 10.82$ & $>0.05$ \\
\hline PT & $8.82 \pm 8.31$ & $11.06 \pm 13.64$ & $>0.05$ \\
\hline SVA & $-20.21 \pm 40.53$ & $-19.24 \pm 32.08$ & $>0.05$ \\
\hline
\end{tabular}

CL: Cervical lordosis, TK: Thoracic kyphosis, LL: Lumbar lordosis, PI: Pelvic incidence, SS: Sacral slope, PT: Pelvic tilt, SVA: Sagittal vertical axis

effect of surgical treatment on SSPs in SK patients exist in literature ${ }^{(10,17)}$. The aim of the surgical treatment for SK is not only the reduction of the deformity but also to obtain a balanced spine. Therefore, the aim of this study was to evaluate SSPs and their changes after surgical treatment of SK. We did not find significant differences between pre- and post-operative SVA, PI, SS, and PT values. Ashraf et al.(1) also evaluated the changes in sagittal spinal and pelvic parameters after surgical treatment in 18 patients with SK. They had similar results to our study. There were no significant changes in PT and SS after surgery as in our study. They reported a direct correlation between LL and TK with significant LL reduction after surgery. There was also a significant change in TK and LL values in our study, as expected. Hosman et al. ${ }^{(10)}$ compared two surgical techniques (combined and posterior-only procedures) for surgical treatment in $33 \mathrm{SK}$ patients. They found no statistically significant differences on SVA between the preoperative and follow-up values in both groups. But they did not evaluate the other SPPs. Different from Hosman et al..$^{(10)}$ we performed surgery by using posterioronly approach which allowed to obtain adequate surgical correction with the advent of modern multisegmental vertebral stabilization systems with pedicle screws ${ }^{(8,18)}$. We had similar results in terms of SVA values with Hosman et al.(10) There were no statistically significant differences between preoperative and follow-up values. Lonner et al. ${ }^{(14)}$ also found no statistically significant differences between anteroposterior and posterioronly surgery in terms of correction magnitude. They also found a correlation between PI an LL, but not between PI and TK. However, we did not evaluate the correlation between SSPs within themselves. On the other hand, in the study of Guler et al.(9) they evaluated the angular and SK patients in terms of SPPs changes after surgical treatment. Although there were no significant differences between preoperative and postoperative values in angular kyphosis group, different from the above-mentioned studies there were statistically significant differences in terms of SS and PT but not in PI. When they compared their study with the literature (studies with the result of no change in SPPs after surgery), they suggested that non-assessment of the impact of kyphotic angle on sacropelvic junction might be the reason for the insignificant effect of surgery on sacropelvic parameters. We also did not evaluate the correlation between SSPs. That may seem as a limitation of current study but we think that it may be a subject of another study. Retrospective study design and short follow- up time may be the limitations of our study.

\section{CONCLUSION}

In conclusion, despite the widespread use of SSPs as a key factor in the good clinical results in the majority of spinal and pelvic disorders, surgical treatment for SK seems to have little or no influence on changing SSPs toward normal values according to the current study and most of the studies in the literature. Surgical correction of SK by Ponte osteotomy and posterior spinal fusion with pedicle screw systems results in the reduction of the kyphosis and of its compensative LL.

\section{Ethics}

Ethics Committee Approval: Retrospective study. Informed Consent: Written informed consent was obtained from all patients.

Peer-review: Internally peer-reviewed.

\section{Authorship Contributions}

Surgical and Medical Practices: Y.A., Concept: S.D., Y.A., Design: B.P., Y.A., Data Collection or Processing: E.Ç., S.E., Y.A., Analysis or Interpretation: S.E., B.P., Literature Search: S.E., Writing: S.E.

Conflict of Interest: No conflict of interest was declared by the authors.

Financial Disclosure: The authors declared that this study received no financial support.

\section{REFERENCES}

1. Ashraf A, Noelle Larson A, Polly DW, Ferski G, Guidera KJ, Mielke $\mathrm{CH}$. Change in Sagittal plane alignment following surgery for Scheuermann's Kyphosis. Spine Deform 2014;2:404-9.

2. Bradford DS, Ahmed KB, Moe JH, Winter RB, Lonstein JE. The surgical management of patients with Scheuermann's disease: a review of twenty-four cases managed by combined anterior and posterior spine fusion. J Bone Joint Surg Am 1980;62:705-12.

3. Cil A, Yazici M, Uzumcugil A, Kandemir U, Alanay A, Alanay $Y$, et al. The evolution of sagittal segmental alignment of the spine during childhood. Spine 2005;30:93-100.

4. Damborg F, Engell V, Andersen M, Kyvik KO, Thomsen K. Prevalence, concordance, and heritability of Scheuermann kyphosis based on a study of twins. J Bone Joint Surg Am 2006;88:2133-6.

5. Eddine TA, Migaud H, Chantelot C, Cotten A, Fontaine C, Duquennoy A. Variations of pelvic anteversion in the lying and standing positions: analysis of 24 control subjects and implications for CT measurement of position of a prosthetic cup. Surg Radiol Anat 2001;23:105-10.

6. El-Hawary R, Sturm PF, Cahill PJ, Samdani AF, Vitale MG, Gabos PG, et al. Sagittal spinopelvic parameters of young children with scoliosis. Spine Deformity 2013;1:343-7

7. Faldini C, Di Martino A, Perna F, Martikos K, Greggi T, Giannini S. Changes in spino-pelvic alignment after surgical treatment of highgrade isthmic spondylolisthesis by a posterior approach: a report of 41 cases. Eur Spine J 2014;23:714-9.

8. Geck MJ, Macagno A, Ponte A, Shufflebarger HL. The Ponte procedure: posterior only treatment of Scheuermann's kyphosis using segmental posterior shortening and pedicle screw instrumentation. J Spinal Disord Tech 2007; 20:586-93. 
9. Guler O, Akgul T, Korkmaz M, Gunerbuyuk C, Sariyilmaz K, Dikici $\mathrm{F}$, et al. Postoperative changes in sacropelvic junction in shortsegment angular kyphosis versus Scheuermann kyphosis. Eur Spine J 2017;3:928-36.

10. Hosman AJ, Langeloo DD, de Kleuver, Anderson PG, Veth RP, Slot $\mathrm{GH}$. Analysis of the sagittal plane after surgical management for Scheuermann's disease: a view on overcorrection and the use of an anterior release. Spine 2002;27:167-75.

11. Labelle H, Roussouly P, Berthonnaud E, Transfeldt E, O'Brien M, Chopin D, et al. Spondylolisthesis, pelvic incidence, and spinopelvic balance: a correlation study. Spine 2004;29:2049-54.

12. Lafage V, Schwab F, Patel A, Hawkinson N, Farcy JP. Pelvic tilt and truncal inclination: two key radiographic parameters in the setting of adults with spinal deformity. Spine 2009;34:599-606.

13. Lee JH, Na KH, Kim JH, Jeong HY, Chang DG. Is pelvic incidence a constant, as everyone knows? Changes of pelvic incidence in surgically corrected adult sagittal deformity. Eur Spine 2016;11:3707-14.

14. Lonner BS, Newton P, Betz R, Scharf C, O'Brien M, Sponseller P, et al. Operative management of Scheuermann's kyphosis in 78 patients: radiographic outcomes, complications, and technique. Spine 2007;32:2644-52.

15. Lowe TG, Line BG. Evidence based medicine: analysis of Scheuermann kyphosis. Spine (Phila Pa 1976) 2007;32 (19 Suppl):115-9.
16. Lowe TG. Scheuermann disease. J Bone Joint Surg Am 1990;72:940-5.

17. Papagelopoulos PJ, Mavrogenis AF, Savvidou OD, Mitsiokapa EA, Themistocleous GS, Soucacos PN. Current concepts in Scheuermann's kyphosis. Orthopedics 2008;31:52-8.

18. Ponte A. Posterior column shortening for Scheuermann's kyphosis: an innovative one-stage technique. Surg Tech Spine N Y Thieme Med 2003:107-13.

19. Ponte A. Posterior shortening procedure by segmental closing wedge osteomies. J Pediatr Orthop 1995;15:404.

20. Roussouly P, Pinheiro-Franco JL. Biomechanical analysis of the spino-pelvic organization and adaptation in pathology. Eur Spine J 2011;20:609-18.

21. Scheuermann HW. The classic: kyphosis dorsalis juvenilis. Clin Orthop Relat Res 1977;5-7.

22. Schwab F, Lafage V, Patel A, Farcy JP. Sagittal plane considerations and the pelvis in the adult patient. Spine 2009;34:1828-33.

23. Sorensen KH. Scheuermann's juvenile kyphosis: clinical appearances, radiography, aetiology, and prognosis. Copenhagen: Munksgaard; 1964

24. Tanguay F, Mac-Thiong JM, de Guise JA, Labelle H. Relation between the sagittal pelvic and lumbar spine geometries following surgical correction of adolescent idiopathic scoliosis. Eur Spine J 2007; 16:531-6. 